KEY WORDS: Tank Sampling

Tank 19

Tank Closure

\title{
Recommendations for Sampling of Tank 19 in F Tank Farm
}

\author{
S. P. Harris \\ E. P. Shine
}

December 14, 2009

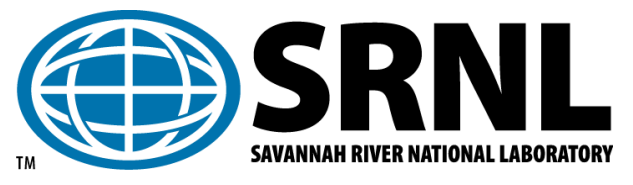

Savannah River National Laboratory

Savannah River Nuclear Solutions

Savannah River Site

Aiken, SC 29808

This document was prepared in conjunction with work accomplished under Contract No. DE-AC09-08SR22470 with the U.S. Department of Energy 


\section{DISCLAIMER}

This work was prepared under an agreement with and funded by the U.S Government. Neither the U. S. Government or its employees, nor any of its contractors, subcontractors or their employees, makes any express or implied: 1. warranty or assumes any legal liability for the accuracy, completeness, or for the use or results of such use of any information, product, or process disclosed; or 2. representation that such use or results of such use would not infringe privately owned rights; or 3. endorsement or recommendation of any specifically identified commercial product, process, or service. Any views and opinions of authors expressed in this work do not necessarily state or reflect those of the United States Government, or its contractors, or subcontractors. 


\section{Reviews and Approvals:}

Authors:

S. P. Harris, Author

Applied Computational Engineering and Statistics

E. P. Shine, Author

Applied Computational Engineering and Statistics

\section{Review/Approval:}

T. B. Edwards, Technical Reviewer

Applied Computational Engineering and Statistics

G. D. Thaxton, Closure Product Engineering Savannah River Remediation

B. A. Martin, Closure \& Disposal Determination Savannah River Remediation

F.M. Pennebaker, Manager

Advanced Characterization \& Processing

P.L. Lee, Manager

Applied Computational Engineering and Statistics
Date

Date

Date

Date

Date

Date 


\section{TABLE OF CONTENTS}

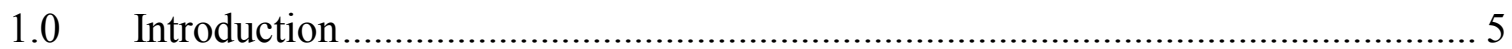

2.0 Previous Sample Plans and Results ........................................................... 5

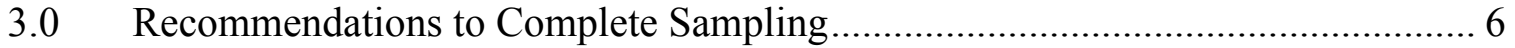

3.1 Analyte Concentration in the Residual Floor Material ..................................... 7

3.2 Upper Confidence Limits on Concentrations......................................................... 8

3.3 Computation of Analyte Concentration Confidence Limits .................................. 9

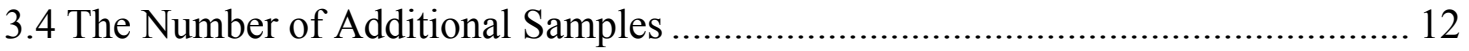

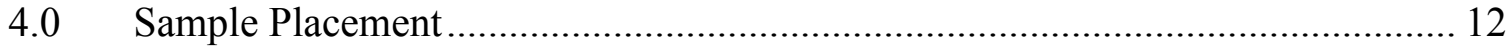

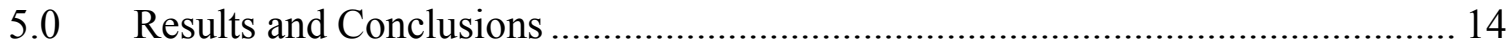

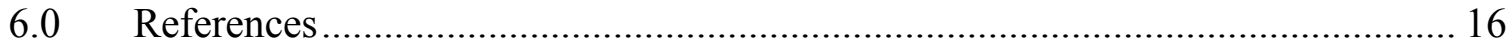

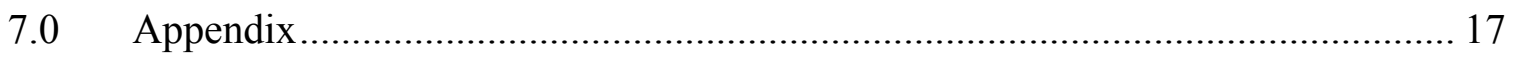

\section{LIST OF TABLES}

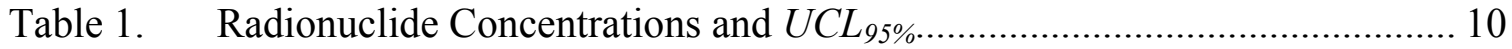

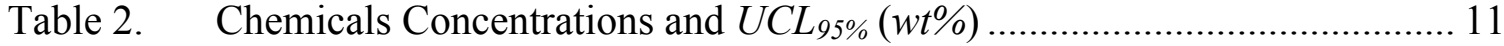

Table 3. Tank 19F Sample Information from the Mantis Rover Samples .................. 17

Table 4. Constituents Below Detection Limits ...................................................... 18

Table 5. Description of Evaluated Radionuclides................................................. 19

Table 6. Description of Evaluated Chemicals .................................................... 20

\section{LIST OF FIGURES}

Figure 1. Layout for additional sampling locations in Tank 19 ................................. 14

Figure 2. Previous Mantis rover sampling locations in Tank 19............................ 21

Figure 3. Tank 19 Floor Scrape Sample Locations (South Hemisphere) ..................... 22

Figure 4. Uncertainty per Additional Samples (All Analytes) .................................... 23

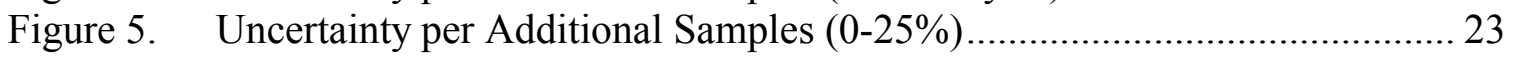

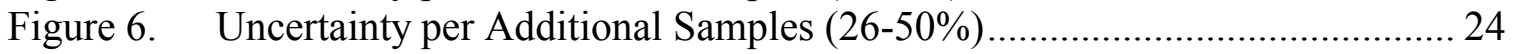

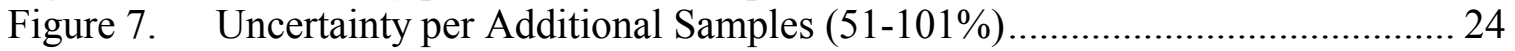

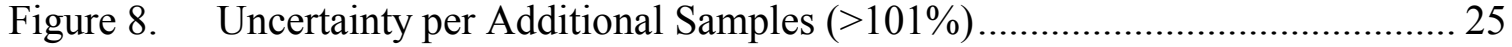




\section{$1.0 \quad$ INTRODUCTION}

Representative sampling is required for characterization of the residual material in Tank 19 prior to operational closure. Tank 19 is a Type IV underground waste storage tank located in the F-Tank Farm. It is a cylindrical-shaped, carbon steel tank with a diameter of 85 feet, a height of 34.25 feet, and a working capacity of 1.3 million gallons. Tank 19 was placed in service in 1961 and initially received a small amount of low heat waste from Tank 17. It then served as an evaporator concentrate (saltcake) receiver from February 1962 to September 1976. Tank 19 also received the spent zeolite ion exchange media from a cesium removal column that once operated in the Northeast riser of the tank to remove cesium from the evaporator overheads.

Recent mechanical cleaning of the tank removed all mounds of material. Anticipating a low level of solids in the residual waste, Huff and Thaxton [2009] developed a plan to sample the waste during the final clean-up process while it would still be resident in sufficient quantities to support analytical determinations in four quadrants of the tank. Execution of the plan produced fewer solids than expected to support analytical determinations in all four quadrants. Huff and Thaxton [2009] then restructured the plan to characterize the residual separately in the North and the South regions: two "hemispheres."

This document provides sampling recommendations to complete the characterization of the residual material on the tank bottom following the guidance in Huff and Thaxton [2009] to split the tank floor into a North and a South hemisphere. The number of samples is determined from a modification of the formula previously published in Edwards [2001] and the sample characterization data for previous sampling of Tank 19 described by Oji [2009]. The uncertainty is quantified by an upper $95 \%$ confidence limit $\left(U C L_{95 \%}\right)$ on each analyte's mean concentration in Tank 19 . The procedure computes the uncertainty in analyte concentration as a function of the number of samples, and the final number of samples is determined when the reduction in the uncertainty from an additional sample no longer has a practical impact on results.

\subsection{PREVIOUS SAMPLE PLANS AND RESULTS}

Early sampling plans to characterize residual waste in tanks scheduled for closure include a statistically-based framework by Edwards [2001] for Tanks 18 and 19, and a more recent sampling application of this framework by Edwards and Shine [2008] for Tanks 5 and 6 . The formulation of sampling uncertainty in these reports allows for separate phases such as separate mounds of radioactive material and distinct non-overlapping regions of the tank that could be separately sampled and analyzed once clean-up efforts were completed.

A sampling and analysis plan for Tanks 18 and 19 was drafted by Huff and Thaxton [2009]. The plan focused on obtaining in-process samples using the Mantis rover. During 
the mechanical cleaning process, waste from Tank 19 was mobilized and transferred by eduction to a Waste Mix Chamber (WMC) in Tank 7. There the waste was ground by an immersion mill grinder to less than 38 microns. Once sufficiently comminuted, the particles floated upward and into a sampler in the WMC.

The original sampling plan called for two in-process vials (samples) of about $125 \mathrm{~mL}$ each from each of four tank quadrants: Northwest, Northeast, Southwest, and Southeast. In addition, a third $125 \mathrm{~mL}$ vial per quadrant was planned as an archival sample as a contingency.

The plan was executed, and the three $125 \mathrm{~mL}$ samples per quadrant were sent to the Savannah River National Laboratory (SRNL). The samples did not yield an adequate quantity of solids to support all of the analytical tests in all four quadrants. Appendix Table 3 lists the amount of solids estimated by SRNL to be in the samples. The entire suite of analytical tests requires approximately 30 grams of solids, although a partial list of key analytes requires only a few grams of solids. As a result, Huff and Thaxton [2009] report that the sampling plan was revised by partitioning the tank into a North and a South hemisphere.

Appendix Table 3 lists the Mantis rover samples (Figure 2) that have been taken from the residual material on the tank floor. The weight of the solids in each of these vials is reported in appendix Table 3 . In addition to the Mantis rover samples, a quality assurance sample was obtained near the center riser slightly within the South hemisphere (Figure 3). The amount of solids in the floor scrape sample was sufficient to support a subset of key analytes. This sample was compared to Mantis rover samples from the South hemisphere in order to ensure that the rover method did not alter the concentrations of the analytes in the solids. The samples were shown to be different just based on analytical uncertainty. However, there may be no difference once sampling variability is considered. The additional floor scrape samples that are recommended in each hemisphere will permit a valid comparison that will include analytical uncertainty and sampling variability.

\subsection{RECOMMENDATIONS TO COMPLETE SAMPLING}

The sampling strategy for Tank 19 to this point in time takes into account possible differences between the North and the South hemispheres, Huff and Thaxton [2009]. A consistent path forward is to determine the quantity of various analytes in the residual material separately for the North and South hemispheres. The total residual material is then the sum of the material in the two hemispheres. Later, if sampling results show that the residual material is similar in the two hemispheres, then the sampling data can be consolidated into a single unit for the entire floor area.

The first stage of the sampling strategy is to determine the number of samples needed to characterize the concentration of analytes in the residual material on the tank floor. A subsequent phase specifies the locations of additional samples, if deemed necessary, to successfully complete the inventory of the residual material on the floor of Tank 19. This 
section outlines the formula for the inventory of residual material for any particular analyte. The following section describes how the sample size is to be determined.

\subsection{Analyte Concentration in the Residual Floor Material}

No distinct mounds of material appear to be left after final cleaning operations. However, the material is stratified into $(i=1)$ North and $(i=2)$ South hemispheres. The formula for the estimated concentration of an analyte for the entire tank floor is

$$
A=\frac{\sum_{i=1}^{2} \bar{a}_{i . .} \bar{\rho}_{i} V_{i}}{\sum_{i=1}^{2} \bar{\rho}_{i} V_{i}},
$$

where $\bar{a}_{i . .}$ is the mean ${ }^{1}$ measured concentration for analyte $a$ in the residual material from stratum $i, i=1,2 ; \bar{\rho}_{i}$ is the mean sample density in stratum $i, i=1,2$; and $V_{i}$ is the volume of residual floor material in stratum $i, i=1,2$. The analyte is measured either wet or dry. Sample material is centrifuged, and the liquid portion is decanted to achieve a wet state. An additional baking step is performed to dry some of the samples. Consequently, either a wet or a dry density is applicable depending on the method of sample preparation. Nearly all laboratory subsamples are in the same state of preparation, wet or dry, when measured for a given analyte. In this report, the estimates of both the wet and dry densities were obtained from Oji [2009]. The density of the samples did not appear to systematically vary by hemisphere, so the density data were pooled in order to obtain a single estimate for the entire tank. The wet density is 1.45 (wet) $\mathrm{g} / \mathrm{mL}$ with a standard deviation of 0.08 (wet) $\mathrm{g} / \mathrm{mL}$, and the dry density is 0.957 (dry)g/mL with a standard deviation of 0.08 (dry)g/mL. The dry density was estimated as the wet cake weight percent total solids times the wet cake density.

The volumes of the residual material in the North hemisphere, approximately 900 gallons, and South hemisphere, approximately 1,100 gallons, was provided by Ludwig [2009]. The volumes were converted to milliliters $(\mathrm{mL})$ by multiplying by 3.7854118 liters/gallon * 1,000 mL/liter. The volume estimates are considered to be best conservative estimates

\footnotetext{
${ }^{1}$ Subscripts $i, j$, and $k$ on measurement $a_{i j k}$ indicates that it represents measurement $k$ on a sample $j$ from a stratum $i$. A dot (.) in place of a subscript represents the sum of all measurements over that subscript, so $a_{i j}$. represents the sum of all measurements on sample $j$ in stratum $i$ since the dot replaces the $k$, and $a_{i .}$. represents the total of all measurements over all samples in stratum $i$ since the dots replace $j$ and $k$. A mean is defined by the sum of a set of measurements divided by the number of measurements in that set, and is identified with a bar $\left(^{-}\right.$) over the italic letter representing a sum of measurements, so
} $\bar{a}_{i j .}=(1 / m) \sum_{k=1}^{m} a_{i j k}$ and $\bar{a}_{i . .}=\left(1 / n_{i}\right) \sum_{j=1}^{n_{i}} \bar{a}_{i j .}=\left(1 /\left(m n_{i}\right)\right) \sum_{j=1}^{n_{i}} \sum_{k=1}^{m} a_{i j k}$ represent the mean of all measurements for just sample $j$ in stratum $i$ and the mean of all measurements in stratum $i, i=1,2$, respectively. 
for the residual material. Therefore, volume uncertainty was not included in the total uncertainty.

\subsection{Upper Confidence Limits on Concentrations}

A one-sided upper 95\% confidence limit is established for analytes that have supporting data (not all less than detection results, for example). Such a limit establishes a credible upper bound on the mean concentration of analyte $a$ in the residual material on the floor of the tank. The formula for the confidence limit is as follows.

$$
U C L_{95 \%}\{A\}=A+t_{0.95, d f} \sqrt{A^{2} S_{A}^{2}},
$$

where $A$ is the concentration of analyte $a$ over the entire tank floor residual and $S_{A}$ is the estimated relative standard error of the mean concentration $A$. The $d f$ in equation (2) is the degrees of freedom associated with $S_{A}$, based on $n_{i}-1$ sampling degrees of freedom in each hemisphere $i=1,2$.

At present there are no established upper concentration specifications for analytes, so the $U C L_{95 \%}$ s cannot be compared to such limits in order to establish the adequacy of the number of samples planned to be taken. The $U C L_{95 \%}$ depends on the sample design (stratification), the number of samples in each stratum, and the number of analytical determinations per sample. An increase in the number of samples or an increase in the number of determinations per sample will generally produce a decrease in the UCL $95 \%$. The analytical method and the amount of sample material available for analyses are also pertinent factors. The incremental effect of one additional sample on reducing the uncertainty in the concentration estimate diminishes as more samples are added. A series of charts and tables has been constructed in order to ascertain the number of samples needed.

In order to place the results on a common scale and more easily visualize the results, each $U C L_{95 \%}$ is converted to a relative uncertainty by taking the ratio of the length of the onesided confidence interval to the mean concentration A for analyte $a$,

$$
\operatorname{RelUCL_{95\% }}=100 \% \frac{U C L_{95 \%}\{A\}-A}{A}
$$

The relative $U C L_{95 \%}$ is a measure of the uncertainty in $A$ relative to its value; it is equal to $t_{0.95, d f} S_{A}$. The relative $U C L_{95 \%}$ is a better measure than the relative standard error of $\mathrm{A}$, $S_{A}$, since small samples sizes affect the value of $t_{0.95, d f}$ (through its degrees of freedom $d f$ ) as well as through the value of the estimated standard error of $A$.

The standard error of the concentration, $A$, depends on estimates of the concentration 
error standard deviation (accounts for sample preparation variation as well as measurement error), and the sampling variation within Tank 19. The analytical error standard deviation was determined from available replicate determinations. The sampling standard deviation was approximated by the standard deviation of the sample means. In many cases this meant the sampling standard deviation depended on the difference between the North and South Mantis sample means, the only source of sampling variation available. This is a conservative approach since the North and South hemispheres potentially have systematic differences in concentration. For a few analytes, the use of hemisphere differences may have inflated the sampling error within each hemisphere during the planning process.

\subsection{Computation of Analyte Concentration Confidence Limits}

Table 1 lists all radionuclides that have sufficient measurements (except Ni-59) to compute an $U C L_{95 \%}$. The table is based on the North and South hemisphere Mantis rover samples and the South hemisphere QA floor scrape sample. The South hemisphere concentration is a simple average of the South Mantis and South floor scrape sample concentrations, when a determination was performed on both samples; it is equal to the lone sample average, if only one of the two South samples was measured for the analyte. The North hemisphere concentration was based solely on the North Mantis sample concentration average. The estimated tank concentration was an average of the North hemisphere and the South hemisphere concentration averages, weighted for the volume of the residual material in each hemisphere. The estimated concentrations are in $\mu \mathrm{Ci} / \mathrm{g}$. The units of grams in the denominator are either "wet" or "dry", depending on the state of the samples when measured and conform to those reported in Oji [2009].

The baseline sample plan refers to the current status of having one Mantis sample in each hemisphere and a QA floor scrape sample in the South hemisphere; no additional sampling was assumed for the baseline sampling plan. The $U C L_{95 \%}$ in the table applies to the baseline sample plan. The $U C L_{95 \%}$ for an analyte $a$ is the upper $95 \%$ confidence limit for the actual mean tank concentration, $A$, for analyte $a$. The $95 \%$ level of confidence refers to the reliability of the method, in that $95 \%$ of such upper confidence values will correctly bound the actual mean concentration of an analyte $a$.

Ni-59 was a special case since it has no $U C L_{95 \%}$. All six Ni-59 determinations on the North Mantis sample were above detection and all six determinations were below detection for the South Mantis samples while Ni-59 was not measured for the floor scrape sample. Pu-240 was only measured for the floor scrape sample. Analogous to Table 1, Table 2 lists all non-radioactive chemicals (except Ni) that have sufficient measurements from the baseline sampling plan to compute an $U C L_{95 \%}$. All six Ni determinations on the South Mantis sample were below detection. Again, the $U C L_{95 \%}$ refers to the baseline sampling plan with no additional sampling. Non-radioactive chemical concentrations are reported in $\mathrm{wt} \%$. 
Table 1. Radionuclide Concentrations ${ }^{2}$ and $U C L L_{95 \%}$ for the Baseline Sample Plan (No Additional Sampling) $(\mu \mathrm{Ci} / \mathrm{g})$

\begin{tabular}{|c|c|c|c|c|}
\hline Radionuclide & $\begin{array}{c}\text { Mean of } \\
\text { North } \\
\text { Hemisphere } \\
\text { Samples } \\
\end{array}$ & $\begin{array}{c}\text { Mean of South } \\
\text { Hemisphere } \\
\text { Samples }\end{array}$ & $\begin{array}{c}\text { Estimated } \\
\text { Tank } \\
\text { Concentration } \\
\end{array}$ & $\begin{array}{c}\text { UCL95\% for } \\
\text { Concentration } \\
\end{array}$ \\
\hline Am-241 & $6.82 \mathrm{E}-01$ & $1.11 \mathrm{E}-01$ & $3.67 \mathrm{E}-01$ & $2.37 \mathrm{E}+00$ \\
\hline Am-242m & $9.10 \mathrm{E}-06$ & $3.53 \mathrm{E}-06$ & $6.03 \mathrm{E}-06$ & $3.03 \mathrm{E}-05$ \\
\hline Am-243 & $4.39 \mathrm{E}-04$ & $2.19 \mathrm{E}-04$ & $3.17 \mathrm{E}-04$ & $1.02 \mathrm{E}-03$ \\
\hline Ba-137m & $6.58 \mathrm{E}+02$ & $5.92 \mathrm{E}+02$ & $6.21 \mathrm{E}+02$ & $1.00 \mathrm{E}+03$ \\
\hline $\mathrm{C}-14$ & 4.87E-03 & $1.27 \mathrm{E}-02$ & $9.15 \mathrm{E}-03$ & $3.85 \mathrm{E}-02$ \\
\hline $\mathrm{Cm}-244$ & $3.12 \mathrm{E}-02$ & $1.45 \mathrm{E}-02$ & $2.20 \mathrm{E}-02$ & $7.51 \mathrm{E}-02$ \\
\hline Co-60 & $5.18 \mathrm{E}-03$ & $2.42 \mathrm{E}-03$ & $3.66 \mathrm{E}-03$ & $1.24 \mathrm{E}-02$ \\
\hline Cs-135 & $4.36 \mathrm{E}-03$ & $4.03 \mathrm{E}-03$ & $4.18 \mathrm{E}-03$ & $5.62 \mathrm{E}-03$ \\
\hline Cs-137 & $6.83 \mathrm{E}+02$ & $6.77 \mathrm{E}+02$ & $6.80 \mathrm{E}+02$ & $1.00 \mathrm{E}+03$ \\
\hline Eu-154 & $2.46 \mathrm{E}-03$ & $4.49 \mathrm{E}-04$ & $1.35 \mathrm{E}-03$ & $8.33 \mathrm{E}-03$ \\
\hline $\mathrm{Ni}-59$ & $2.58 \mathrm{E}-03$ & & & \\
\hline $\mathrm{Ni}-63$ & $1.94 \mathrm{E}-01$ & $6.31 \mathrm{E}-03$ & $9.06 \mathrm{E}-02$ & $8.29 \mathrm{E}-01$ \\
\hline $\mathrm{Np}-237$ & $5.11 \mathrm{E}-05$ & $8.53 \mathrm{E}-05$ & $6.99 \mathrm{E}-05$ & $1.63 \mathrm{E}-04$ \\
\hline $\mathrm{Pu}-238$ & 3.42E-01 & $2.25 \mathrm{E}-01$ & $2.77 \mathrm{E}-01$ & $6.60 \mathrm{E}-01$ \\
\hline $\mathrm{Pu}-239$ & 4.91E-01 & $2.81 \mathrm{E}-01$ & $3.75 \mathrm{E}-01$ & $10.3 \mathrm{E}-01$ \\
\hline $\mathrm{Pu}-239 / 240$ & $6.00 \mathrm{E}-01$ & $3.46 \mathrm{E}-01$ & $4.60 \mathrm{E}-01$ & $1.25 \mathrm{E}+00$ \\
\hline $\mathrm{Pu}-241$ & $7.81 \mathrm{E}-01$ & $6.09 \mathrm{E}-01$ & $6.86 \mathrm{E}-01$ & $1.23 \mathrm{E}+00$ \\
\hline $\mathrm{Sb}-126$ & $2.37 \mathrm{E}-04$ & $2.46 \mathrm{E}-04$ & $2.42 \mathrm{E}-04$ & $2.91 \mathrm{E}-04$ \\
\hline $\mathrm{Sb}-126 \mathrm{~m}$ & $2.37 \mathrm{E}-04$ & $2.46 \mathrm{E}-04$ & $2.42 \mathrm{E}-04$ & $2.91 \mathrm{E}-04$ \\
\hline Sm-151 & $4.38 \mathrm{E}-02$ & $1.29 \mathrm{E}-02$ & $2.67 \mathrm{E}-02$ & $1.49 \mathrm{E}-01$ \\
\hline Sn-126 & $2.37 \mathrm{E}-04$ & $2.46 \mathrm{E}-04$ & $2.42 \mathrm{E}-04$ & $2.91 \mathrm{E}-04$ \\
\hline Sr-90 & $1.52 \mathrm{E}+00$ & $4.22 \mathrm{E}-01$ & $9.15 \mathrm{E}-01$ & $4.72 \mathrm{E}+00$ \\
\hline Tc-99 & $2.95 \mathrm{E}-02$ & $1.99 \mathrm{E}-02$ & $2.42 \mathrm{E}-02$ & $5.80 \mathrm{E}-02$ \\
\hline Th-232 & $2.04 \mathrm{E}-07$ & $2.04 \mathrm{E}-07$ & $2.04 \mathrm{E}-07$ & $2.21 \mathrm{E}-07$ \\
\hline U-232 & $7.25 \mathrm{E}-06$ & $5.02 \mathrm{E}-06$ & $6.02 \mathrm{E}-06$ & $1.33 \mathrm{E}-05$ \\
\hline U-234 & $9.71 \mathrm{E}-04$ & $3.48 \mathrm{E}-04$ & $6.28 \mathrm{E}-04$ & $3.10 \mathrm{E}-03$ \\
\hline U-235 & $1.47 \mathrm{E}-05$ & $1.30 \mathrm{E}-05$ & $1.37 \mathrm{E}-05$ & $2.00 \mathrm{E}-05$ \\
\hline U-236 & $2.24 \mathrm{E}-05$ & $1.79 \mathrm{E}-05$ & $1.99 \mathrm{E}-05$ & $3.21 \mathrm{E}-05$ \\
\hline U-238 & $4.28 \mathrm{E}-04$ & $3.53 \mathrm{E}-04$ & $3.87 \mathrm{E}-04$ & $6.06 \mathrm{E}-04$ \\
\hline Y-90 & $1.52 \mathrm{E}+00$ & $4.22 \mathrm{E}-01$ & $9.15 \mathrm{E}-01$ & $2.03 \mathrm{E}+00$ \\
\hline
\end{tabular}

2 The units of measure for concentration match those reported by SRNL in Oji [2009]. If the sample was prepared "wet", then the denominator unit of measure is "wet" grams, and if the sample was prepared "dry", then the denominator unit of measure is "dry" grams. 
Table 2. Chemicals Concentrations and $U C L L_{95 \%}(w t \%)$ for the Baseline Sample Plan (No Additional Sampling)

\begin{tabular}{|l|r|r|r|r|}
\hline Chemical & $\begin{array}{c}\text { Mean of North } \\
\text { Hemisphere } \\
\text { Samples }\end{array}$ & $\begin{array}{c}\text { Mean of South } \\
\text { Hemisphere } \\
\text { Samples }\end{array}$ & $\begin{array}{c}\text { Estimated } \\
\text { Tank } \\
\text { Concentration }\end{array}$ & $\begin{array}{c}\text { UCL95\% for } \\
\text { Concentration }\end{array}$ \\
\hline $\mathrm{Al}$ & $1.67 \mathrm{E}+01$ & $1.51 \mathrm{E}+01$ & $1.58 \mathrm{E}+01$ & $2.34 \mathrm{E}+01$ \\
\hline $\mathrm{Ba}$ & $9.12 \mathrm{E}-02$ & $8.99 \mathrm{E}-02$ & $9.05 \mathrm{E}-02$ & $1.49 \mathrm{E}-01$ \\
\hline $\mathrm{C}_{2} \mathrm{O}_{4}^{-2}$ & $5.05 \mathrm{E}+02$ & $1.39 \mathrm{E}+03$ & $9.91 \mathrm{E}+02$ & $4.32 \mathrm{E}+03$ \\
\hline $\mathrm{Ca}$ & $6.86 \mathrm{E}-01$ & $7.44 \mathrm{E}-01$ & $7.18 \mathrm{E}-01$ & $1.28 \mathrm{E}+00$ \\
\hline $\mathrm{Cd}$ & $2.68 \mathrm{E}-02$ & $7.94 \mathrm{E}-03$ & $1.64 \mathrm{E}-02$ & $8.19 \mathrm{E}-02$ \\
\hline $\mathrm{CO}^{-2}$ & $5.05 \mathrm{E}+03$ & $1.93 \mathrm{E}+03$ & $3.33 \mathrm{E}+03$ & $1.56 \mathrm{E}+04$ \\
\hline $\mathrm{Cr}$ & $1.99 \mathrm{E}-02$ & $3.07 \mathrm{E}-02$ & $2.58 \mathrm{E}-02$ & $7.41 \mathrm{E}-02$ \\
\hline $\mathrm{F}^{-1}$ & $1.85 \mathrm{E}+02$ & $8.37 \mathrm{E}+01$ & $1.29 \mathrm{E}+02$ & $4.55 \mathrm{E}+02$ \\
\hline $\mathrm{Fe}$ & $3.91 \mathrm{E}+00$ & $3.53 \mathrm{E}+00$ & $3.70 \mathrm{E}+00$ & $5.60 \mathrm{E}+00$ \\
\hline $\mathrm{Hg}$ & $1.78 \mathrm{E}-02$ & $6.66 \mathrm{E}-03$ & $1.16 \mathrm{E}-02$ & $4.77 \mathrm{E}-02$ \\
\hline $\mathrm{Mg}$ & $3.34 \mathrm{E}-01$ & $2.31 \mathrm{E}-01$ & $2.77 \mathrm{E}-01$ & $6.80 \mathrm{E}-01$ \\
\hline $\mathrm{Mn}$ & $1.29 \mathrm{E}-01$ & $1.11 \mathrm{E}-01$ & $1.19 \mathrm{E}-01$ & $1.98 \mathrm{E}-01$ \\
\hline $\mathrm{Na}^{-1}$ & $8.61 \mathrm{E}+00$ & $8.46 \mathrm{E}+00$ & $8.53 \mathrm{E}+00$ & $1.34 \mathrm{E}+01$ \\
\hline $\mathrm{Ni}^{-1.17 \mathrm{E}-02}$ & & & \\
\hline $\mathrm{Si}$ & $1.20 \mathrm{E}+01$ & $1.12 \mathrm{E}+01$ & $1.16 \mathrm{E}+01$ & $1.45 \mathrm{E}+01$ \\
\hline $\mathrm{SO}{ }_{4}^{-2}$ & $1.37 \mathrm{E}+02$ & $9.05 \mathrm{E}+01$ & $1.12 \mathrm{E}+02$ & $1.24 \mathrm{E}+02$ \\
\hline $\mathrm{Sr}$ & $1.51 \mathrm{E}-02$ & $1.47 \mathrm{E}-02$ & $1.49 \mathrm{E}-02$ & $4.58 \mathrm{E}-01$ \\
\hline $\mathrm{Ti}$ & $7.08 \mathrm{E}-02$ & $6.98 \mathrm{E}-02$ & $7.02 \mathrm{E}-02$ & $8.43 \mathrm{E}-02$ \\
\hline $\mathrm{U}^{\mathrm{Zn}}$ & $1.59 \mathrm{E}-01$ & $1.20 \mathrm{E}-01$ & $1.38 \mathrm{E}-01$ & $2.59 \mathrm{E}-01$ \\
\hline $\mathrm{NO}_{2}{ }^{-1}$ & $6.29 \mathrm{E}-03$ & $5.40 \mathrm{E}-03$ & $5.80 \mathrm{E}-03$ & $1.23 \mathrm{E}-02$ \\
\hline $\mathrm{NO}_{3}{ }^{-1}$ & $1.50 \mathrm{E}+02$ & $9.76 \mathrm{E}+01$ & $1.21 \mathrm{E}+02$ & $2.85 \mathrm{E}+02$ \\
\hline $\mathrm{Zr}$ & $2.81 \mathrm{E}+03$ & $2.66 \mathrm{E}+03$ & $2.73 \mathrm{E}+03$ & $3.43 \mathrm{E}+03$ \\
\hline & $9.85 \mathrm{E}-03$ & $9.30 \mathrm{E}-03$ & $9.55 \mathrm{E}-03$ & $2.10 \mathrm{E}-02$ \\
\hline
\end{tabular}

Table 4 in the appendix lists all constituents, radionuclides and chemicals, on which every concentration measurement was reported as a less than detection. Appendix Table 5 and Table 6 are a complete accounting of every radionuclide and chemical, respectively, reported in Oji [2009], along with a description of the data: all measurements (above detection limits), all measurements reported as less than detection, or a mix of the two. It also contains a column reporting whether the analysis was conducted on a "wet" or a "dry" sample.

Besides the baseline sampling plan, addition sampling plans were considered with 1, 2, 3, 4, 5, 6 and 10 additional samples in each hemisphere. In each of these plans, the number of analyses on each of the added samples was assumed to be three since additional measurements were shown to provide very little reduction in the UCL $95 \%$. The relative $U C L_{95 \%}$ from formula (3) was computed for each analyte under each of these sampling scenarios. This measures the total range of uncertainty in an analyte's concentration that 
lies above the estimated concentration. If the sample size had been extremely large, the relative $U C L_{95 \%}$ would decrease to near zero.

The analytes were divided into subsets depending on the size of the relative $U C L_{95 \%}$ for the case of 1 additional sample per hemisphere. The group with a relative $U C L_{95 \%}$ up to $25 \%$ is shown in appendix Figure 5. The plot shows the relative $U C L_{95 \%}$ decreasing as the number of additional samples increases. The large drop between 1 and 2 additional samples per hemisphere is followed by a series of much smaller decreases in the relative $U C L_{95 \%}$.

Appendix Figure 6 through Figure 8 display the results for analytes with a relative $U C L_{95 \%}$ between $26 \%$ and $50 \%, 51 \%$ to $101 \%$, and greater than $101 \%$, respectively. All plots exhibit the same characteristic, with the drops in the relative $U C L_{95 \%}$ decreasing after 3 additional samples per hemisphere (6 new samples analyzed).

It should be noted that the sampling variance in many cases was computed from the difference between the North and South Mantis sample concentration means. This difference could be large simply because the actual concentration of an analyte was very different between the two hemispheres. Figure 8 captures the largest relative $U C L_{95 \%}$ values, and may be dominated by actual hemisphere concentration differences, rather than the intended sampling error variation or within hemisphere differences.

\subsection{The Number of Additional Samples}

The final sample size is determined when the reduction in uncertainty from an additional sample no longer has a practical impact on the results. Assume the baseline sample plan, one Mantis sample in each hemisphere and one South floor scrape sample, can be used as a starting point. The plot in Appendix Figure 4 displays the decrease in uncertainty as more and more additional samples and analyses are obtained. Figure 5 pertains to just the analytes which have relative uncertainties no greater than $25 \%$. The decrease becomes smaller and smaller as more samples are added. Six additional samples were selected as a point of diminishing returns. In addition to the six samples, two more samples will be obtained and archived, bringing the final number of additional samples to eight. If the Mantis samples cannot be demonstrated to be comparable to floor scrape samples, then the two archived samples will be analyzed. Appendix Figure 6 through Figure 8 have similar patterns of uncertainty reduction, so the same result is obtained. Comparing the uncertainty associated with six additional samples to the uncertainty with 20 additional samples (the latter representing an intensively sampled scenario) in these figures, it can be seen that more than half of the reduction in uncertainty is already achieved with just six additional samples.

\subsection{SAMPLE PLACEMENT}

The recommendations that follow are based on two observations. First, if the Mantis samples are to be used, they must be demonstrated to have similar characteristics to floor 
scrape samples, that is, the Mantis sampling procedure should not have altered the concentration of analytes in the solids. If shown to be comparable, the Mantis rover and floor scrape sample information can all be used to support the quantification of analytes in the residual material. Otherwise, the Mantis samples should not be used in final concentration estimates, and an additional sample should be obtained and archived as a contingency for the Mantis samples.

Second, previous work has assumed that analyte concentrations may differ between the North and South hemispheres, and so each hemisphere should be sampled independently. Then, only after a comparison of samples in the two hemispheres demonstrates similarities relative to sampling variation, should the results from the entire tank be consolidated into a single unit. If the results from the North and the South hemispheres cannot be demonstrated to be similar, then the sampling plan must support separate quantification of the analyte concentrations in the two hemispheres.

The following recommendations may be subject to physical tank access and sampling constraints affecting the placement of additional samples. Partition the Tank 19 floor into an inner and an outer ring and six $60^{\circ}$ sectors as depicted in Figure 1. The location of the border between the inner and outer rings is based on dividing the residual material into two approximately equal volumes. There will be a total of four samples from each hemisphere including the new samples to be archived once the additional sampling has been completed. In order to balance the samples between the inner and outer rings (two samples in each ring per hemisphere), two samples should be taken from the outer ring in the North hemisphere and two samples should be taken from the outer ring in the South hemisphere. One sample to be analyzed should be obtained from the inner ring of each hemisphere. The two additional samples slated to be archived should also be taken from the inner ring, since they are the primary contingency if the Mantis samples (from the inner ring) are demonstrated to be incompatible with the other sample results. One of the archived samples should be taken in each hemisphere. The choice of $60^{\circ}$ sector for archived samples should be made so at least one sample to be analyzed is located in each sector regardless of whether the Mantis samples are used. 


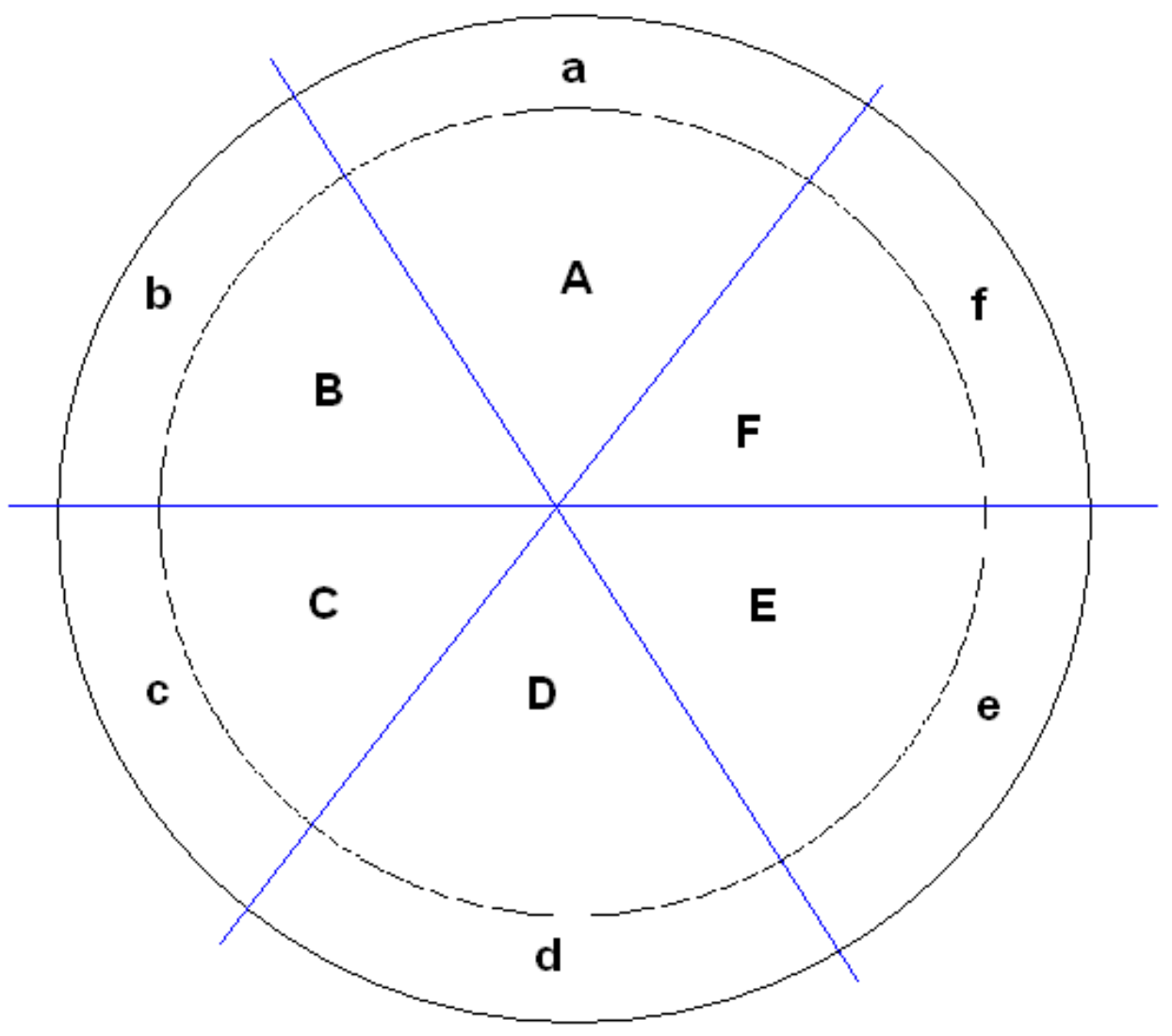

Figure 1. Layout for additional sampling locations in Tank 19

\subsection{RESULTS AND CONCLUSIONS}

The characterization of the full suite of analytes in the North and South hemispheres is currently supported by a single Mantis rover sample in each hemisphere. A floor scrape sample was obtained from a compact region near the center riser slightly in the South hemisphere and has been analyzed for a shortened list of key analytes. There is not enough additional material from the floor scrape sample material for completing the full suite of constituents. No floor scrape samples have been previously taken from the North hemisphere.

The criterion to determine the number of additional samples was based on the practical reduction in the uncertainty when a new sample is added. This was achieved when five additional samples are obtained. In addition, two archived samples will be used if a contingency such as failing to demonstrate the comparability of the Mantis samples to the floor scrape samples occurs.

To complete sampling of the Tank 19 residual floor material, four additional samples 
should be taken from the North hemisphere and four additional samples should be taken from the South hemisphere. One of the samples from each hemisphere will be archived in case of need. Three of the four additional samples from each hemisphere will be analyzed. Once the results are available, differences between the Mantis and three floor scrape sample results will be evaluated. If there are no statistically significant analyte concentration differences between the Mantis and floor scrape samples, those results will be combined and then $U C L_{95 \%} \mathrm{~S}$ will be calculated. If the analyte concentration differences between the Mantis and floor scrape samples are statistically significant, the $U C L_{95 \% \mathrm{~S}}$ will be calculated without the Mantis sample results. If further reduction in the upper confidence limits is needed and can be achieved by the addition of the archived samples, they will be analyzed and included in the statistical computations.

Initially the analyte concentrations in the residual material on the floor of Tank 19 will be determined separately in the North and the South hemispheres. However, if final sampling results show that differences between the North and South samples are consistent within sampling variation, then the final computations can be based on consolidating all sample results from the tank floor.

Recommended locations may be subject to physical tank access and sampling constraints for the additional samples. The recommendations have been discussed in Section 4 and are based on partitioning the Tank 19 floor into an inner and an outer ring and six $60^{\circ}$ sectors depicted in Figure 1. The location of the border between the inner and outer rings is based on dividing the residual material into two approximately equal volumes. Apart from the new samples to be archived, there will be four floor samples (Mantis and scrape) from each hemisphere once the additional sampling has been completed. In order to balance the samples between the inner and outer rings two samples will be taken from the inner ring and two samples will be taken from the outer ring in each hemisphere. Two of the eight samples, one from each hemisphere, will be archived. The samples slated to be archived (1 from each hemisphere) should also be obtained from the inner ring, since they are the primary contingency if the Mantis samples (from the inner ring) are demonstrated to be incompatible with the other sample results. 


\subsection{REFERENCES}

[2009] Barbour, K. Drawing of Previous Sample Locations and Available Entry Locations, personal e-mail communication.

[2001] Edwards, T.B., "A Decision Support Tool for Planning the Sampling of Tank 19 (U),” WSRC-RP-2001-00781, Revision 0, July 2001.

[2008] Edwards, T.B. and Shine, E.P. "Preliminary Statistical Support for Sampling Tanks 5 and 6“, Draft SRNL-L5100-2008-00007, Savannah River Site, Aiken, SC. (October 22).

[2009] Huff, T. and Thaxton, G.D. Draft of "Tanks 18 and 19 Waste Determination Sample Plan," LWO-LWE-2008-00186, Revision 2, Savannah River Site, Aiken, SC. (June 22).

[2009] Ludwig, W. "Waste Tanks 18 \& 19 Maps and Volumes," e-mail communication to E.P. Shine (November 22).

[2009] Oji, L.N., et. al. "Characterization of Tank 19F Closure Samples," SRNL-STI2009-00700 Rev. 0., Savannah River National Laboratory, Aiken, SC. (November $13)$.

[2005] Thomas, J.L. "Characterization of Tank 18 Residual Waste," Technical Report UTR-F-00005, Rev. 2, Savannah River Site, (August). 


\subsection{APPENDIX}

Table 3. Tank 19F Sample Information from the Mantis Rover Samples

\begin{tabular}{|c|c|c|c|c|}
\hline \multicolumn{4}{|c|}{ NORTH (24) Quadrant } & \multirow[b]{2}{*}{ Location } \\
\hline ID & Estimated wt., g & Date received & Comments & \\
\hline FTF-19-09-24-1 & 3 & $4 / 7 / 2009$ & Composited & Sample 1 North \\
\hline FTF-19-09-24-2 & 6 & $4 / 7 / 2009$ & Composited & Sample 1 North \\
\hline FTF-19-09-24-3 & 6 & $4 / 7 / 2009$ & Composited & Sample 1 North \\
\hline FTF-19-09-24-4 & 6 & $4 / 7 / 2009$ & Composited & Sample 1 North \\
\hline FTF-19-09-24-5 & 8 & $4 / 7 / 2009$ & Composited & Sample 1 North \\
\hline FTF-19-09-24-6 & 5 & $4 / 7 / 2009$ & Composited & Sample 1 North \\
\hline FTF-19-09-24-7 & 4 & $4 / 7 / 2009$ & Composited & Sample 1 North \\
\hline FTF-19-09-24-8 & 2 & $4 / 7 / 2009$ & Archived & Sample 1 North \\
\hline FTF-19-09-24-9 & 3 & $4 / 7 / 2009$ & Archived & Sample 1 North \\
\hline FTF-19-09-28-1 & 3 & $4 / 20 / 2009$ & Composited & Sample 2 North \\
\hline FTF-19-09-28-2 & 3 & $4 / 20 / 2009$ & Composited & Sample 2 North \\
\hline FTF-19-09-28-3 & 4 & $4 / 20 / 2009$ & Composited & Sample 2 North \\
\hline \multicolumn{4}{|c|}{ SOUTH (25) Quadrant } & \\
\hline ID & Estimated wt., g & Date received & Comments & Location \\
\hline FTF-19-09-25-1 & 2 & $4 / 8 / 2009$ & Composited & Sample 1 South \\
\hline FTF-19-09-25-2 & 8 & $4 / 14 / 2009$ & Composited & Sample 1 South \\
\hline FTF-19-09-25-3 & 4 & $4 / 14 / 2009$ & Composited & Sample 1 South \\
\hline FTF-19-09-25-4 & 2 & $4 / 8 / 2009$ & Archived & Sample 1 South \\
\hline FTF-19-09-25-5 & 2 & $4 / 8 / 2009$ & Archived & Sample 1 South \\
\hline FTF-19-09-25-6 & 2 & $4 / 8 / 2009$ & Composited & Sample 1 South \\
\hline FTF-19-09-25-7 & 2 & $4 / 8 / 2009$ & Composited & Sample 1 South \\
\hline FTF-19-09-25-8 & 3 & $4 / 14 / 2009$ & Composited & Sample 1 South \\
\hline FTF-19-09-25-9 & 2 & $4 / 8 / 2009$ & Composited & Sample 1 South \\
\hline FTF-19-09-29-1 & 4 & $4 / 22 / 2009$ & Composited & Sample 2 South \\
\hline FTF-19-09-29-2 & 4 & $4 / 22 / 2009$ & Composited & Sample 2 South \\
\hline FTF-19-09-29-3 & 6 & $4 / 22 / 2009$ & Composited & Sample 2 South \\
\hline FTF-19-09-29-4 & 4 & $4 / 22 / 2009$ & Composited & Sample 2 South \\
\hline FTF-19-09-29-5 & 4 & $4 / 22 / 2009$ & Composited & Sample 2 South \\
\hline FTF-19-09-29-6 & $\begin{array}{c}\text { Open sample not } \\
\text { used }\end{array}$ & $4 / 22 / 2009$ & $\mathrm{~N} / \mathrm{A}$ & Sample 2 South \\
\hline
\end{tabular}

3 Oji [2009] 
Table 4. Constituents Below Detection Limits

\begin{tabular}{|c|c|}
\hline Radionuclides & Chemicals \\
\hline Ac-227 & $\overline{\mathrm{Ag}}$ \\
\hline Al-26 & As \\
\hline $\mathrm{Ce}-144$ & B \\
\hline Cf-249 & $\mathrm{Be}$ \\
\hline Cf-251 & $\mathrm{Ce}$ \\
\hline Cf-252 & $\mathrm{Cu}$ \\
\hline CHO2-1 & $\mathrm{Gd}$ \\
\hline $\mathrm{C}_{1}^{-1}$ & $\mathrm{~K}$ \\
\hline $\mathrm{Cm}-243$ & $\mathrm{La}$ \\
\hline $\mathrm{Cm}-245$ & $\mathrm{Li}$ \\
\hline $\mathrm{Cm}-247$ & $\mathrm{P}$ \\
\hline $\mathrm{Cm}-248$ & $\mathrm{~Pb}$ \\
\hline Cs-134 & $\mathrm{S}$ \\
\hline Eu-152 & $\mathrm{Sb}$ \\
\hline Eu-155 & $\mathrm{Se}$ \\
\hline Gross alpha & $\mathrm{Sn}$ \\
\hline H-3 & $\mathrm{V}$ \\
\hline I-129 & \\
\hline $\mathrm{Na}-22$ & \\
\hline $\mathrm{Nb}-94$ & \\
\hline $\mathrm{Pa}-231$ & \\
\hline Pm-147 & \\
\hline $\mathrm{PO}_{4}^{-3}$ & \\
\hline Pr-144 & \\
\hline $\mathrm{Pu}-242$ & \\
\hline $\mathrm{Pu}-244$ & \\
\hline Ra-226 & \\
\hline Ra-228 & \\
\hline Rh-106 & \\
\hline Ru-106 & \\
\hline Sb-125 & \\
\hline Se-79 & \\
\hline $\mathrm{Te}-125 \mathrm{~m}$ & \\
\hline Th-229 & \\
\hline Th-230 & \\
\hline U-232 & \\
\hline U-233 & \\
\hline U-233 & \\
\hline U-234 & \\
\hline
\end{tabular}


Table 5. Description of Evaluated Radionuclides

\begin{tabular}{|c|c|c|}
\hline Radionuclide & Data Description & Measurement Type \\
\hline Am-241 & All Measured & Wet \\
\hline Am- $242 m$ & Measured and Below Detection Combined & Wet \\
\hline Am-243 & All Measured & Wet \\
\hline $\mathrm{Ba}-137 \mathrm{~m}$ & All Measured & Dry \\
\hline $\mathrm{C}-14$ & All Measured & Wet \\
\hline $\mathrm{Cm}-244$ & All Measured & Wet \\
\hline Co-60 & All Measured & Wet \\
\hline Cs-135 & All Measured & Dry \\
\hline Cs- 137 & All Measured & Dry \\
\hline Eu-154 & All Measured & Wet \\
\hline $\mathrm{Ni}-59$ & All Measured in North, All Below Detection in South & Wet \\
\hline $\mathrm{Ni}-63$ & All Measured & Wet \\
\hline Np-237 & All Measured & Dry \\
\hline $\mathrm{Pu}-238$ & All Measured & Dry \\
\hline $\mathrm{Pu}-239$ & All Measured & Dry \\
\hline $\mathrm{Pu}-239 / 240$ & All Measured & Dry \\
\hline $\mathrm{Pu}-240$ & All Measured & Dry \\
\hline $\mathrm{Pu}-241$ & All Measured & Dry \\
\hline Sb-126 & All Measured & Wet \\
\hline $\mathrm{Sb}-126 \mathrm{~m}$ & All Measured & Wet \\
\hline Sm-151 & All Measured & Dry \\
\hline Sn-126 & All Measured & Wet \\
\hline Sr-90 & All Measured & Dry \\
\hline Tc-99 & All Measured & Wet \\
\hline Th-232 & Measured and Below Detection Combined & Dry \\
\hline U-232 & All Measured & Dry \\
\hline U-234 & All Measured & Dry \\
\hline $\mathrm{U}-235$ & All Measured & Dry \\
\hline U-236 & All Measured & Dry \\
\hline U-238 & All Measured & Dry \\
\hline Y-90 & All Measured & Dry \\
\hline
\end{tabular}


Table 6. Description of Evaluated Chemicals

\begin{tabular}{|c|c|c|}
\hline Chemical & Data Description & Measurement Type \\
\hline $\mathrm{Al}$ & All Measured & Dry \\
\hline $\mathrm{Ba}$ & All Measured & Dry \\
\hline $\mathrm{C}_{2} \mathrm{O}_{4}^{-2}$ & All Measured & Wet \\
\hline $\mathrm{Ca}$ & All Measured & Dry \\
\hline $\mathrm{Cd}$ & Measured and Below Detection Combined & Dry \\
\hline $\mathrm{CO}_{3}^{-2}$ & All Measured & Wet \\
\hline $\mathrm{Cr}$ & Measured and Below Detection Combined & Dry \\
\hline $\mathrm{F}^{-1}$ & All Measured & Wet \\
\hline $\mathrm{Fe}$ & All Measured & Dry \\
\hline $\mathrm{Hg}$ & All Measured & Dry \\
\hline $\mathrm{Mg}$ & All Measured & Dry \\
\hline $\mathrm{Mn}$ & All Measured & Dry \\
\hline $\mathrm{Na}$ & All Measured & Dry \\
\hline $\mathrm{Ni}$ & Measured and Below Detection Combined & Dry \\
\hline $\mathrm{Si}$ & All Measured & Dry \\
\hline $\mathrm{SO}_{4}^{-2}$ & All Measured & Wet \\
\hline $\mathrm{Sr}$ & All Measured & Dry \\
\hline $\mathrm{Ti}$ & All Measured & Dry \\
\hline $\mathrm{U}$ & Measured and Below Detection Combined & Dry \\
\hline $\mathrm{Zn}$ & All Measured & Dry \\
\hline $\mathrm{NO}_{2}^{-1}$ & All Measured & Wet \\
\hline $\mathrm{NO}_{3}^{-1}$ & All Measured & Wet \\
\hline $\mathrm{Zr}$ & All Measured & Dry \\
\hline
\end{tabular}




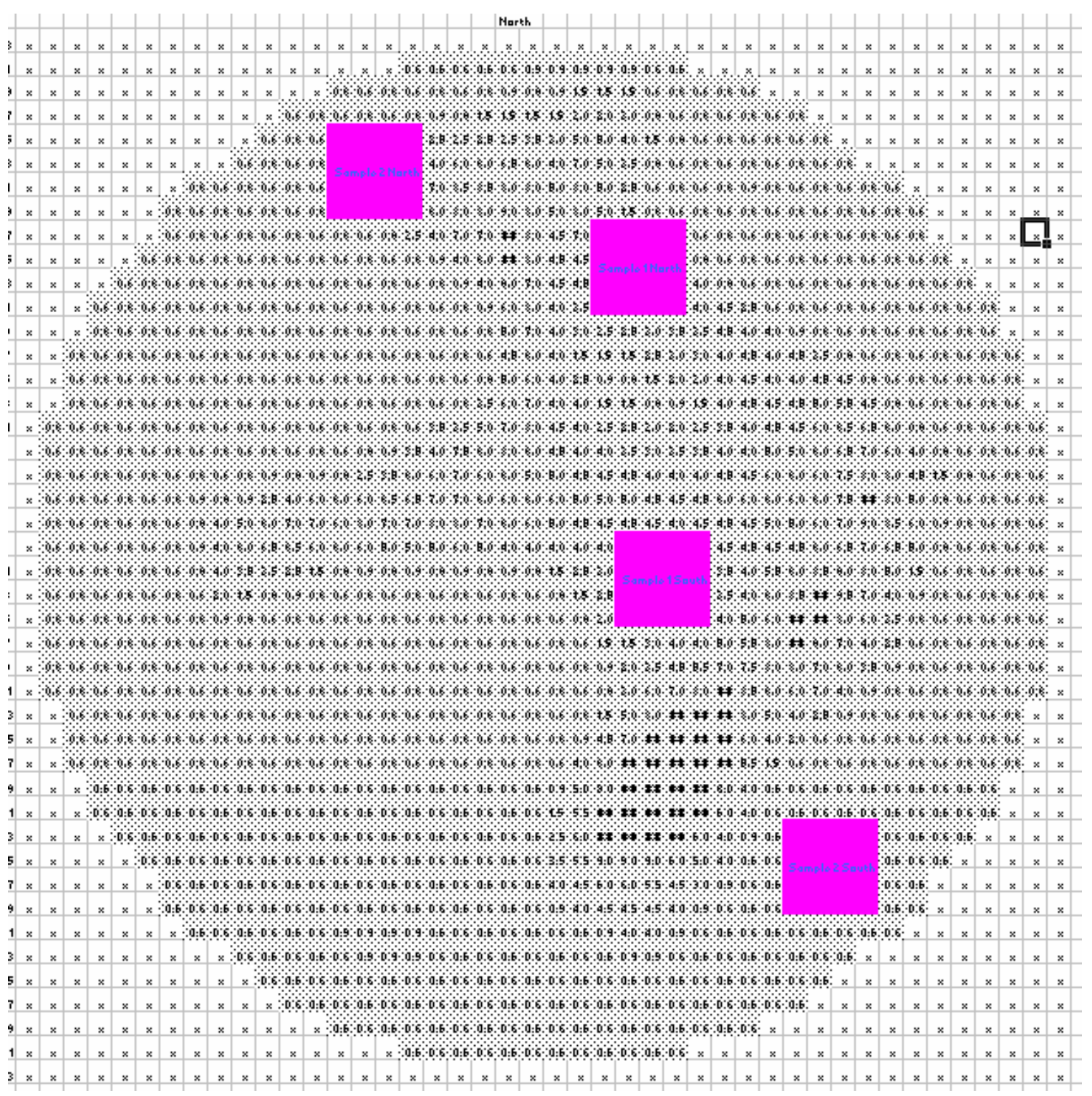

Figure 2. Previous ${ }^{1}$ Mantis rover sampling locations in Tank $19^{2}$

${ }^{1}$ Each of the squares forming the grid is 2-by-2 feet square.

2 Table information from E-mail communication from K. Barbour, Type IV Tank Closure

Organization, August 10, 2009. 


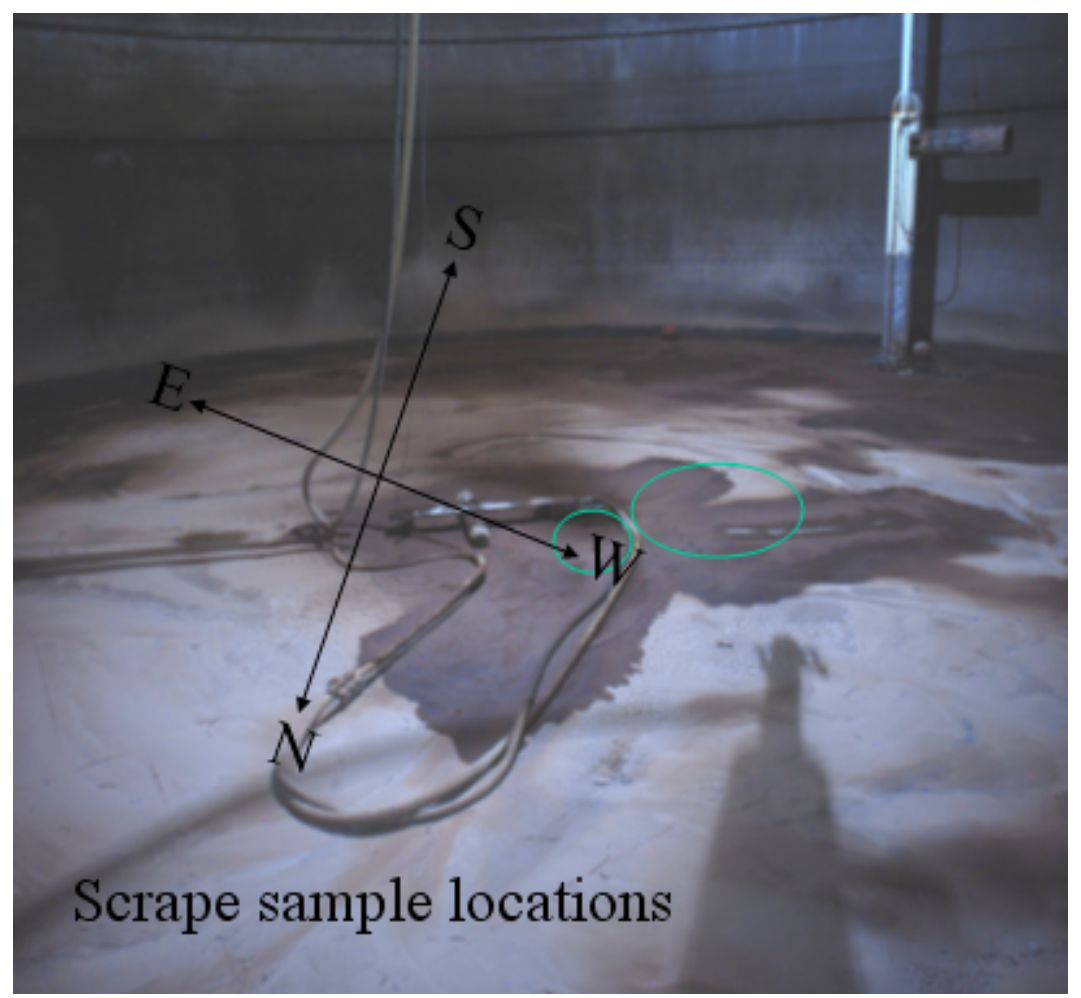

Figure 3. Tank 19 Floor Scrape Sample Locations (South Hemisphere) 


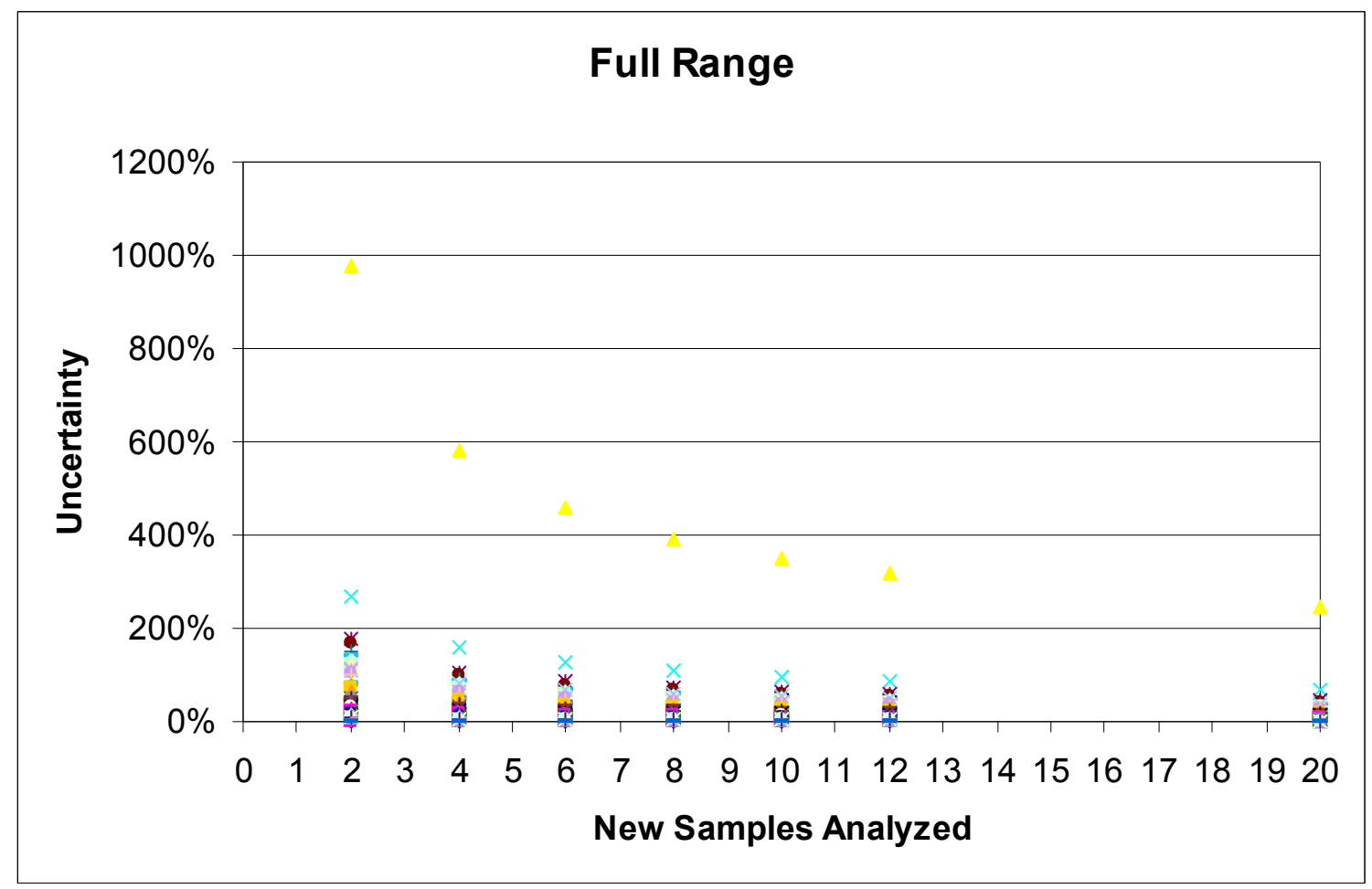

Figure 4. Uncertainty per Additional Samples (All Analytes)

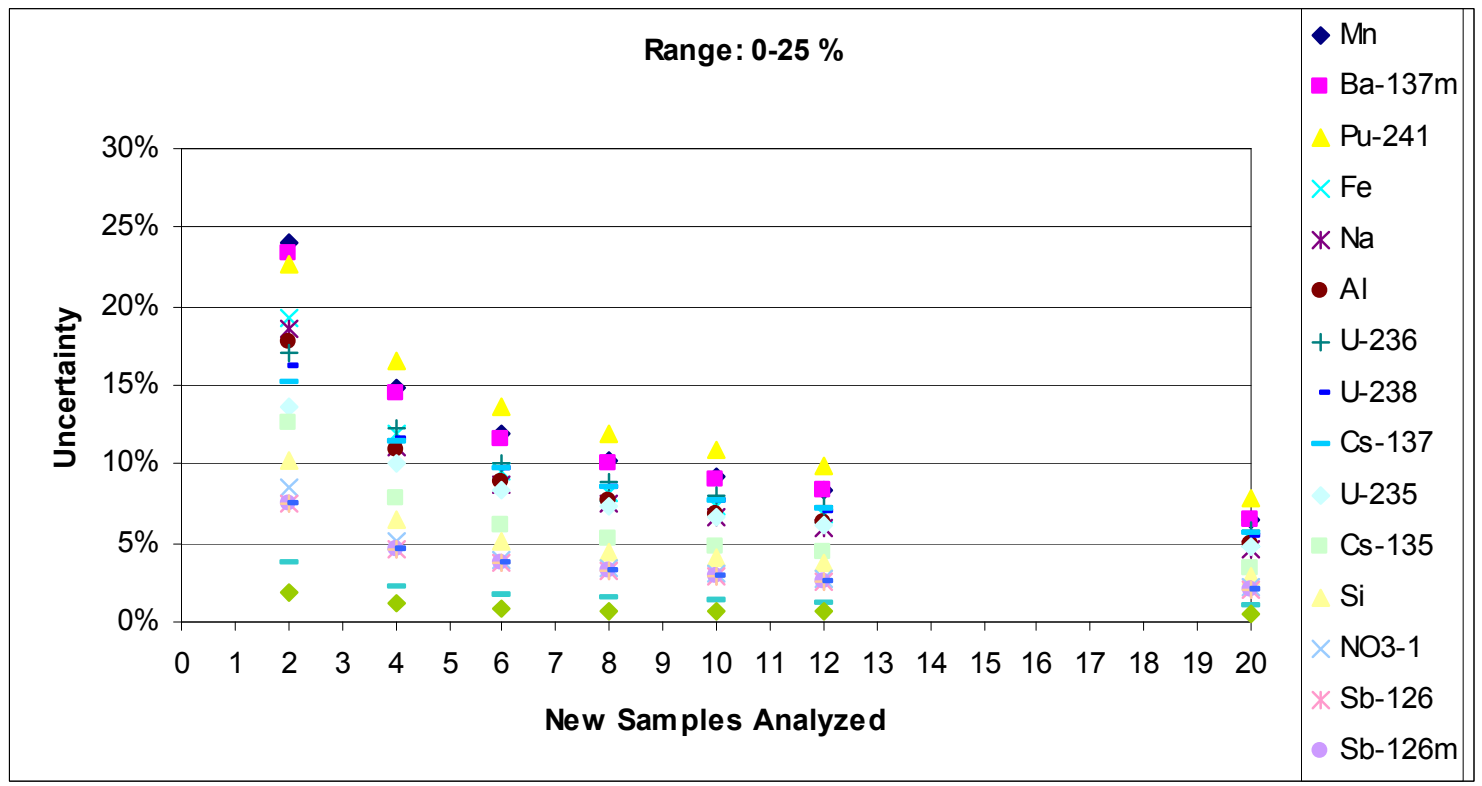

Figure 5. Uncertainty per Additional Samples (0-25\%) 


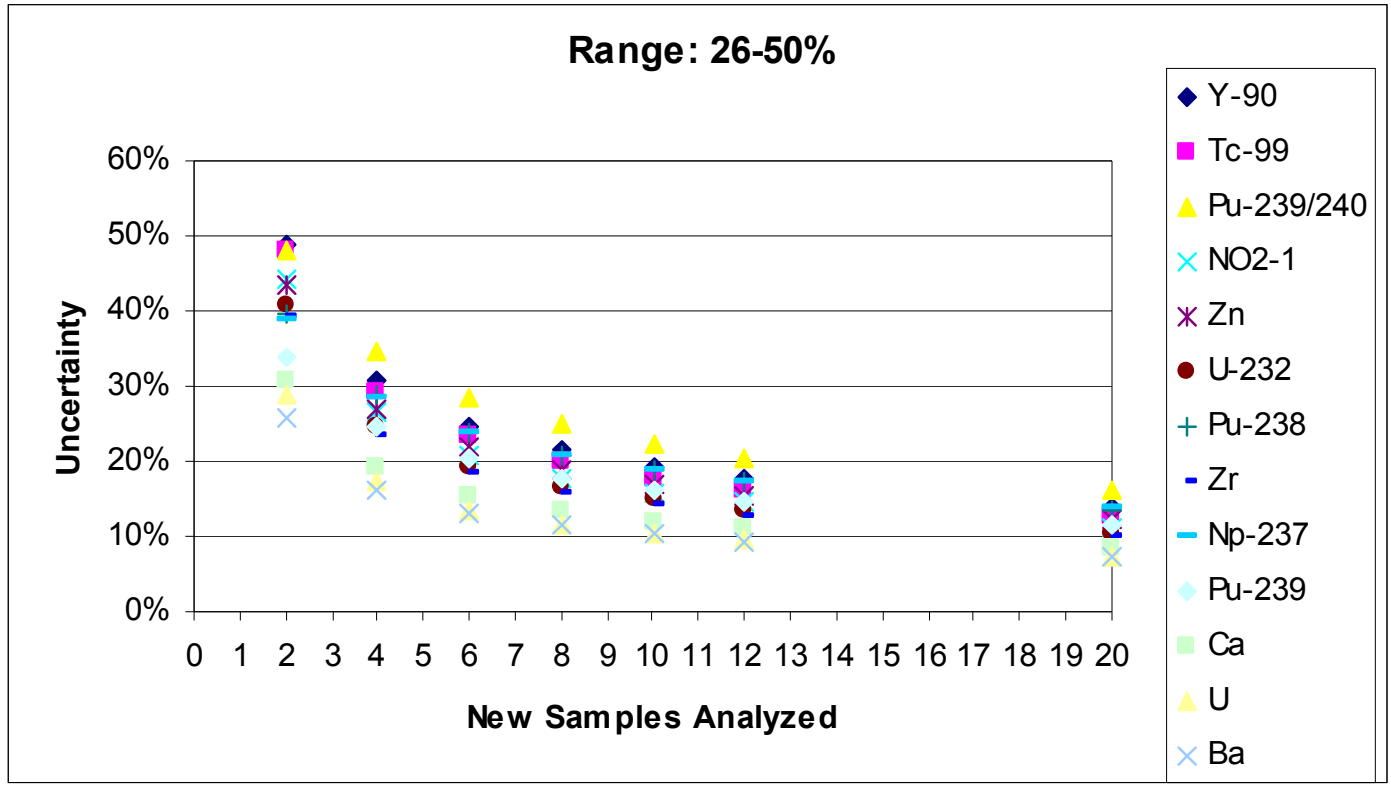

Figure 6. Uncertainty per Additional Samples (26-50\%)

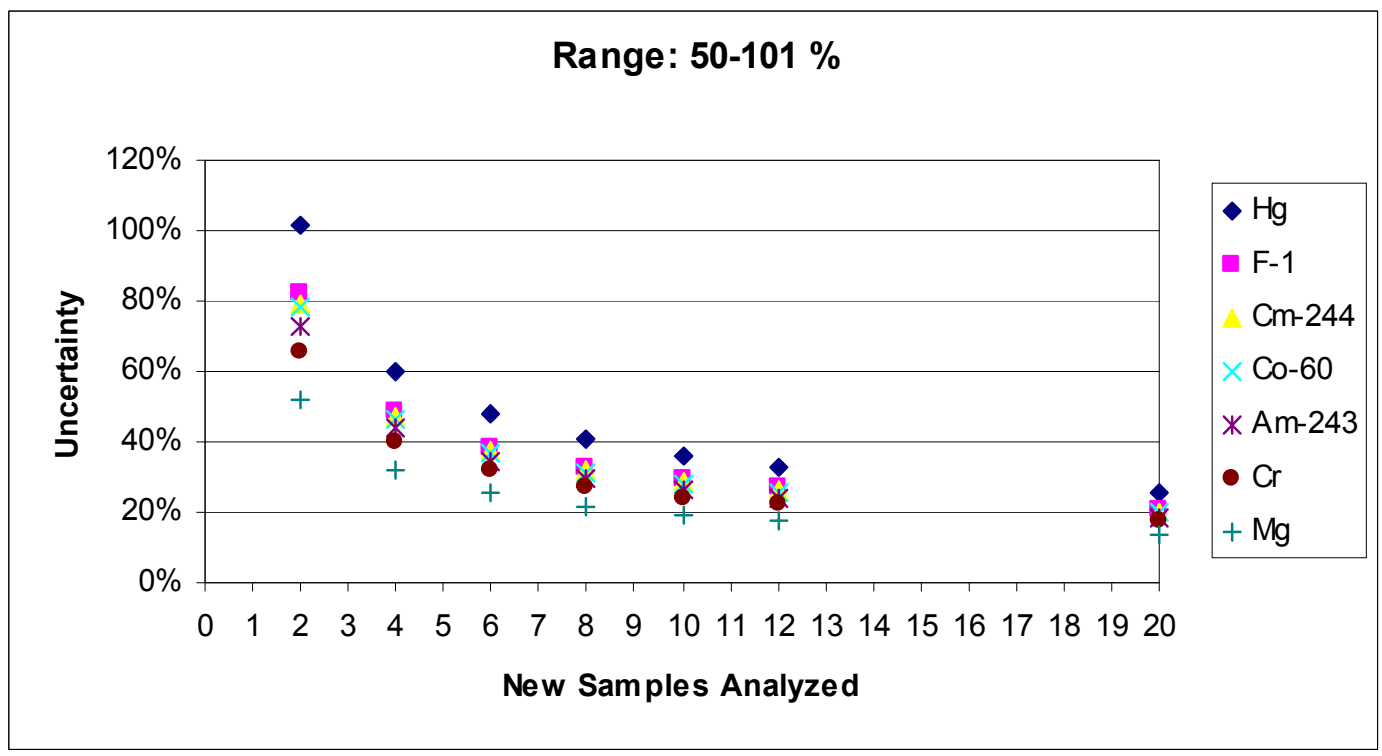

Figure 7. Uncertainty per Additional Samples (51-101\%) 


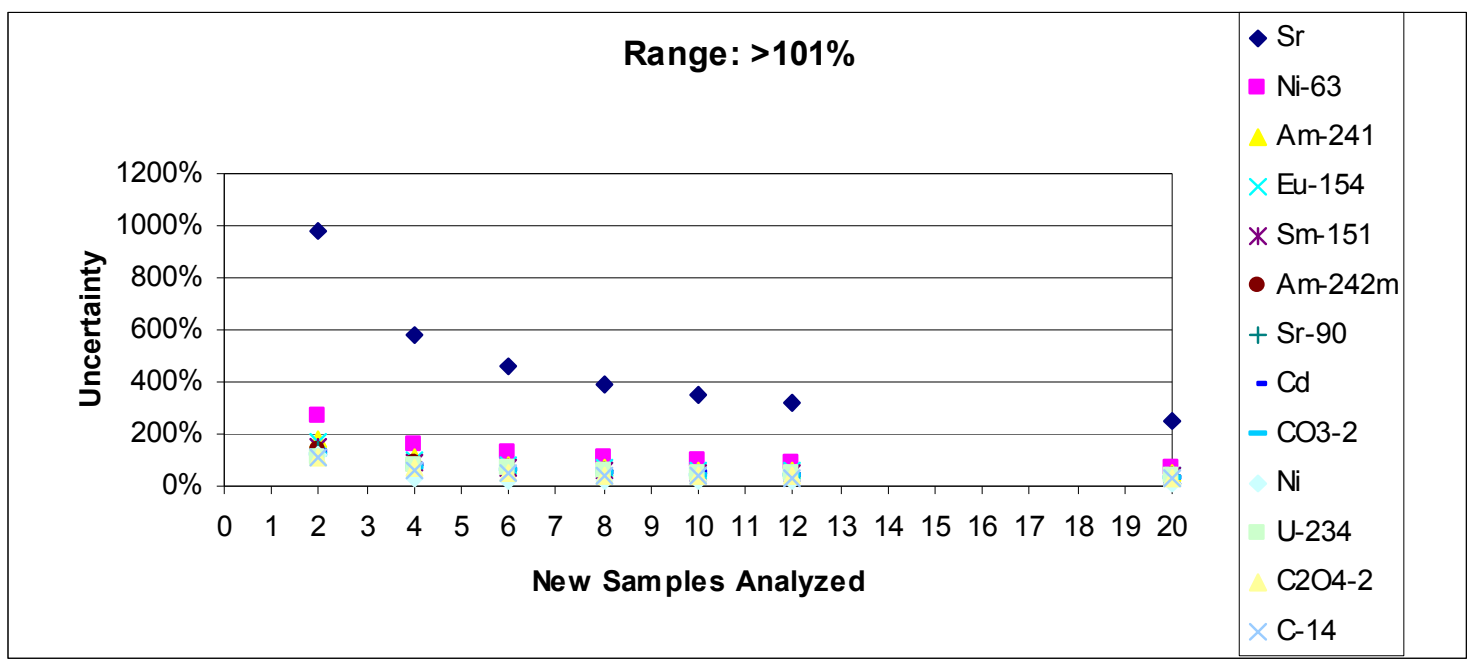

Figure 8. Uncertainty per Additional Samples (>101\%) 


\section{Recommendations for Completing Tank 19 Sampling}

\section{Distribution:}

$\underline{\text { Savannah River Remediation }}$

B.A. Martin, 704-70F Closure and Waste Determination Authority

W.L. Isom, 704-26F Manager, Closure Project Engineering

G.D. Thaxton, 704-70F Closure Project Engineering

K.H. Barbour, 704-70F Type IV Tank Closure

J.E. Herbert, 241-108F Closure Projects

A.J. Tisler, 704-26F Closure Project Engineering

D.A. Broaden, 241-102F Type IV Tank Closure

G.C. Arthur, 704-70F Closure Project Engineering

D.J. Clark, 241-109F Bulk Sludge Removal

$\underline{\text { Savannah River National Laboratory }}$

F.M. Pennebaker, 773-42A Manager, Advanced Characterization \& Processing

P.L. Lee, 773-42A Manager, Applied Computational Engineering and Statistics

T. B. Edwards, 773-42A Applied Computational Engineering and Statistics

S.J. Hensel, 773-42A Manager, Applied Computational Engineering and Sciences 